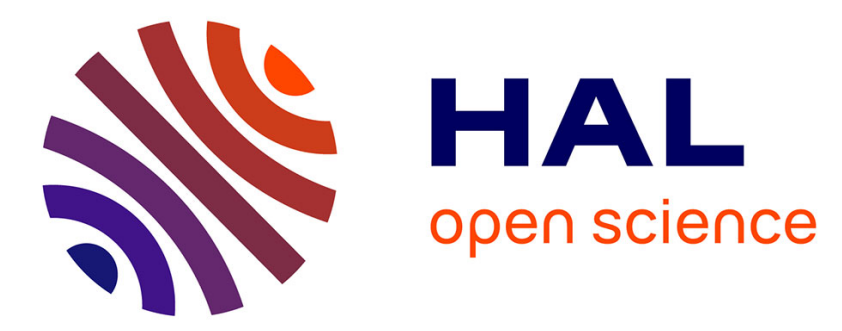

\title{
Energy-based modelling to assess effects of chemicals on Caenorhabditis elegans: A case study on uranium
}

\author{
Benoit Goussen, Rémy Beaudouin, Morgan Dutilleul, Adeline \\ Buisset-Goussen, Jean-Marc Bonzom, Alexandre R.R. Pery
}

\section{To cite this version:}

Benoit Goussen, Rémy Beaudouin, Morgan Dutilleul, Adeline Buisset-Goussen, Jean-Marc Bonzom, et al.. Energy-based modelling to assess effects of chemicals on Caenorhabditis elegans: A case study on uranium. Chemosphere, 2015, 120, pp.507 - 514. 10.1016/j.chemosphere.2014.09.006 . hal-01083767

\section{HAL Id: hal-01083767 https://hal.science/hal-01083767}

Submitted on 17 Nov 2014

HAL is a multi-disciplinary open access archive for the deposit and dissemination of scientific research documents, whether they are published or not. The documents may come from teaching and research institutions in France or abroad, or from public or private research centers.
L'archive ouverte pluridisciplinaire HAL, est destinée au dépôt et à la diffusion de documents scientifiques de niveau recherche, publiés ou non, émanant des établissements d'enseignement et de recherche français ou étrangers, des laboratoires publics ou privés. 


\title{
Energy-based modelling to assess effects of chemicals on Caenorhabditis elegans: a case study on uranium
}

\author{
Benoit Goussen* 1,2 ${ }^{2}$ Rémy Beaudouin ${ }^{1}$, Morgan Dutilleul ${ }^{2}$, Adeline \\ Buisset-Goussen ${ }^{2}$, Jean-Marc Bonzom ${ }^{2}$, and Alexandre R.R. PÉRY ${ }^{1}$ \\ ${ }^{1}$ Unité Modèles pour l'Ecotoxicologie et la Toxicologie (METO), Institut National de l'Environnement Industriel et des Risques \\ (INERIS), BP2, F-60550 Verneuil en Halatte, France \\ 2 Institut de Radioprotection et de Sûreté Nucléaire (IRSN), PRP-ENV, SERIS, Laboratoire d'ECOtoxicologie des radionucléides \\ (LECO), Cadarache, France
}

NOTICE: this is the author's version of a work that was accepted for publication in Chemosphere. Changes resulting from the publishing process, such as peer review, editing, corrections, structural formatting, and other quality control mechanisms may not be reflected in this document. Changes may have been made to this work since it was submitted for publication. A definitive version was subsequently published in Chemosphere: Goussen B., Beaudouin R., Dutilleul M., Buisset-Goussen A., Bonzom J.-M., Péry A.R.R. (2015) Energy-based modelling to assess effects of chemicals on Caenorhabditis elegans: a case study on uranium. Chemosphere. 120:507-514. DOI j.chemosphere.2014.09.006.

\section{Abstract}

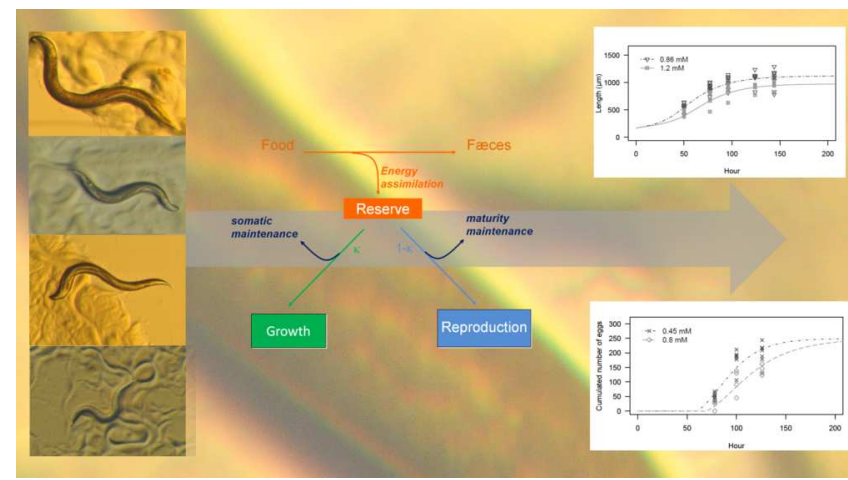

The ubiquitous free-living nematode Caenorhabditis elegans is a powerful animal model for measuring the evolutionary effects of pollutants which is increasingly used in (eco)toxicological studies. Indeed, toxicity tests with this nematode can provide in a few days data on the whole life cycle. These data can be analysed with mathematical tools such as toxicokinetictoxicodynamic modelling approaches. In this study, we assessed how a chronic exposure to a radioactive heavy metal (uranium) affects the life-cycle of $C$. elegans using a mechanistic model. In order to achieve this, we exposed individuals to a range of seven concentrations of uranium. Growth and reproduction were followed daily. These data were analysed with a model for nematodes based on the Dynamic Energy Budget theory, able to handle a wide range of plausible biological parameters values. Parameter estimations were performed using a Bayesian framework. Our results showed that uranium affects the assimilation of energy from food with a no-effect concentration (NEC) of $0.42 \mathrm{mM} \mathrm{U}$ which would be the threshold for effects on both growth and reproduction. The sensitivity analysis showed that the main contributors to the model output were parameters linked to the feeding processes and the actual exposure concentration. This confirms that the real exposure concentration should be measured accurately and that the feeding parameters should not be fixed, but need to be reestimated during the parameter estimation process.

\section{Highlights}

- We proposed an improved bioenergetic model to assess effects on nematodes

- The numerical behaviour of this model was evaluated

- The model proved to handle a wide range of plausible biological parameters values

- Uranium is likely to decrease the assimilation of energy by $C$. elegans

Keywords: Caenorhabditis elegans - Dynamic Energy Budget - Bayesian - Numerical behaviour - Uranium

*Corresponding author. Email: benoit.goussen@gmail.com 


\section{Introduction}

The evaluation of the long term effects of pollutants on the environment is required for an effective protection of the ecosystems. According to Yeates and Bongers (1999), a useful bioindicator of ecosystemic stress should be the nematodes since they are abundant key decomposers in soil ecosystem. Within this phylum, a powerful animal model for measuring the effects of pollutant is the ubiquitous free-living nematode Caenorhabditis elegans. It measures $250 \mu \mathrm{m}$ at hatching and up to $1.4 \mathrm{~mm}$ at adult stage. It has several advantages for ecotoxicological assessment such as (i) a short life cycle (C. elegans breeds in three days after hatching at $20^{\circ} \mathrm{C}$ ), (ii) a short life span (21 days at $20^{\circ} \mathrm{C}$ ), and (iii) a high fecundity (Byerly et al., 1976). C. elegans allows the assessment of life-history traits such as length, reproduction, or survival at various time steps during an experimentation. Therefore, this nematode is widely used to produce data for the assessment of chemical effects on the environment (Boyd et al., 2010; Dutilleul et al., 2013; Goussen et al., 2013; Smith et al., 2009; Swain et al., 2010).

The assessment of (eco)toxicological data through models based on the Dynamic Energy Budget (DEB) theory (Billoir et al., 2008b; Kooijman and Bedaux, 1996), known as DEBtox models is relevant to assess the effects of toxic compounds on organisms. Indeed, this method allows the simultaneous modelling of multiple endpoints (growth and reproduction) and the parameters estimated are independent of the exposure time (Billoir et al., 2008b; Jager et al., 2004). Such models can be used to assess physiological modifications (e.g. changes in growth rate, maximal length, reproduction rate, cumulated reproduction) (Augustine et al., 2012a; Billoir et al., 2008a; Massarin et al., 2011), or differential life strategy responses (Alda Álvarez et al., 2005) of an organism exposed to a pollutant. DEB modelling can also be adapted to other types of analysis. Thereby, individual based model (IBM) based on DEB modelling can permit to analyse population level data, especially multi-generation studies (Beaudouin et al., 2012; Martin et al., 2013).

Uranium, a pollutant of growing interest (OECD, International Atomic Energy Agency (IAEA), 2012), is a radioactive heavy metal that can be found naturally in the environment. It is both a chemical and a radiological toxic but its chemical toxicity is considered to be dominant (Sheppard et al., 2005; Zeman et al., 2008).

We recently produced multi-generation data for nematodes exposed to uranium (Goussen et al., 2013). These data will be analysed with a DEBtox model for nematodes. Prior to this, we had to propose a relevant and robust DEBtox modelling approach for nematodes. This is the aim of this paper.

Jager et al. (2005) presented a DEB model applied to the nematode. This model has been adapted to the assessment of ecotoxicological data (resulting in a so called DEBtox model) and used several times (Alda Ál- varez et al., 2006, 2005; Swain et al., 2010). In the present study, we proposed an augmented version of the DEBtox equations for nematodes by Jager et al. (2005) based on biological characteristics that were not covered. We evaluated both nematode DEBtox models to analyse data on the effects of the uranium on the free living nematode Caenorhabditis elegans. We also assessed the output robustness and sensitivity to parameters.

\section{Materials and Methods}

Experimental data were extracted from (Goussen et al., 2013). Extended description is presented in supplementary information.

\subsection{Model description}

The Dynamic Energy Budget (DEB) theory (Kooijman, 2010) is based on a mathematical description of the uptake and use of energy within an organism. The general DEB framework generally predicts that individuals' growth follows a von Bertalanffy growth curve provided feeding is ad libitum or at constant density (Kooijman, 2010) and the growth is isomorphic (i.e. the organism shape do not change with growth). However as demonstrated by Byerly et al. (1976), C. elegans growth curve deviates from the expected von Bertalanffy curve. According to Knight et al. (2002), the $C$. elegans buccal cavity grows in a stepwise manner at each moult whereas the rest of the body growth is linear between the moults. Knight et al. (2002) assumed that this process induces a food limitation thus resulting in an initial growth slower than the later growth. Jager et al. (2005) dealt with this particularity assuming the $C$. elegans ingestion rate follows a size-dependent feeding limitation function and incorporated this in their nematode DEB model. These authors also assumed an immediate stop of the reproduction when the sperm runs out. Nevertheless, experimental data do not show an immediate stop of reproduction, but rather a more smooth transition (see for example Byerly et al. (1976) Fig. 6 and 8 and Muschiol et al. (2009) Fig. 2). We here propose two modifications of this set of equations in order to take into account some known biological specificities of the nematode. (i) The $C$. elegans male gamete limitation induces a progressive stop of the egg laying (Maupas, 1900; Ward and Carrel, 1979). (ii) We also modified the size-dependent feeding limitation function by adding a new parameter which allows the nematode to access food whatever its length. Indeed, the approach from Jager et al. (2005) assumed that a small nematode would never be able to access enough food to growth if food is just sub-optimal (see section results in this paper). With our approach, we assumed that this nematode will be able to access to a sufficient small quantity of food, such as small bacteria (bacteria is the main food source of $C$. elegans Abada et al., 2009 ), to initiate growth. The set of equations in our DEBtox model for nematodes is thus: 


\subsection{Estimation of the parameters}

$$
\begin{aligned}
& s_{f}(l)=\alpha\left[1-\left(1+\frac{l_{f}^{3}}{l^{3}}\right)^{-1}\right] \\
& \frac{d l}{d t}=r_{B}\left[\left(1-s_{f}\right) f-l\right] \\
& \frac{d R}{d t}=\frac{R_{M}}{1-l_{p}^{3}}\left[\frac{g+l}{g+\left(1-s_{f}\right) f}\left(1-s_{f}\right) f l^{2}-l_{p}^{3}\right] \frac{R_{M a x}-R}{R_{\text {Max }}}
\end{aligned}
$$

with $s_{f}$ the size-dependent ingestion limitation function, $(1-\alpha)(-)$ the proportion of food available whatever the length, $r_{B}\left(\mathrm{~h}^{-1}\right)$ the von Bertalanffy growth rate, $f(-)$ the actual ingestion rate divided by the maximal ingestion rate for a body size, $R$ (\#) the cumulated reproduction, $R_{\text {Max }}$ (\#) the maximal cumulated reproduction, $R_{M}\left(\# \mathrm{~h}^{-1}\right)$ the maximum reproduction rate, and $g(-)$ the investment ratio. $L(\mu \mathrm{m})$ represents the body length at time $t, L_{0}(\mu \mathrm{m})$ the body length at birth (i.e. the start of feeding in the DEB framework), $L_{f}(\mu \mathrm{m})$ the body length at which the ingestion rate is half the maximum ingestion rate, and $L_{p}(\mu \mathrm{m})$ the body length at puberty. All these length data are scaled by the maximal length $L_{\text {inf }}(\mu \mathrm{m})$ resulting in scaled parameters $l, l_{0}, l_{f}$, and $l_{p}(-)$.

The internal concentration of the pollutant scaled by the ratio between the uptake rate and the elimination rate (which can be regarded as the bioconcentration factor; Péry et al., 2001), $c_{q}$, has been calculated as described by Kooijman and Bedaux (1996). These authors described a one-compartment toxicokinetic model with growth dilution, chemical exchanges depending on a surface area:volume ratio, and an elimination rate depending on food availability. This equation has been modified with the $s_{f}$ function resulting in the following equation:

$$
\frac{d c_{q}}{d t}=C \frac{k_{e}\left(1-s_{f}\right) f}{l}-c_{q}\left[\frac{k_{e}\left(1-s_{f}\right) f}{l}+\frac{d \ln l^{3}}{d t}\right]
$$

where $k_{e}\left(\mathrm{~h}^{-1}\right)$ is the elimination rate and $C$ (mM) the real exposure concentration. The toxic stress function, $s$, was calculated as $s\left(c_{q}\right)=$ $\max \left[0, b\left(c_{q}-N E C\right)\right]$ with $b\left(\mathrm{mM}^{-1}\right)$ the slope of the effect and $N E C$ (mM) the no-effect concentration.

Combining Equations 1 with the DEBtox equations rederived from the original ones by Billoir et al. (2008b), we obtained the set of equations presented in Table 1 .

According to a previous study, the uranium negatively affects both the growth and the reproduction of $C$. elegans at comparable exposure concentrations (Goussen et al., 2013). As a consequence, the modes of action that may apply to uranium on nematodes are the growth, assimilation, or maintenance models.
Parameters estimations were performed using the statistical computing software R 2.15 (R Core Team, 2012) and the JAGS 3.3.0 (Just Another Gibbs Sampler) software, which is a program for the statistical analysis of Bayesian hierarchical models by Markov Chain Monte Carlo (MCMC) (Plummer, 2003). The initial parameters' distributions were chosen according to the literature (Jager et al., 2005) (Table 2). We chose positive truncated normal distribution for biological parameters and we applied a coefficient of variation of $20 \%$ to these values. Parameters for which less information was available were distributed according to a non-informative uniform distribution. The different modes of action models were compared using the Deviance Information Criterion (DIC) which is suitable for Bayesian calibration comparison (Spiegelhalter et al., 2002). The DIC is a generalisation of the Akaike's Information Criterion (AIC). As for the AIC, the lower DIC points out the model that will make the best short-term predictions and a DIC difference of less than five indicates that the models show similar fits (Spiegelhalter et al., 2003). The DIC is a penalized deviance statistics as it includes penalty as a function of the effective number of parameters of the model (Spiegelhalter et al., 2002).

\subsection{Sensitivity and uncertainty analysis}

An uncertainty analysis was performed on the model parameters. Parameters' distributions were the same as for the estimation of the parameters apart for the use of triangle distributions instead of normal distributions. The triangle distribution permits a larger exploration of the space of parameters values, because extreme values have higher probability, resulting in a more robust model analysis. The experimental design was built using a Monte Carlo approach. The variances of the model output were estimated by Monte Carlo integrations. Two independent input sample matrices $(n \times p)$ were used to compute the Monte Carlo integration. The sample size $(n)$ was of 30,000 and the number of parameters $(p)$ is indicated in the Table S2 for each model.

We also performed a sensitivity analysis on the parameters using a variance-based Sobol method (scheme by Saltelli (2002)). The sensitivity analysis allows the identification of the main input contributors to the variation of the model outcome. Thus the sensitivity analysis indicates the parameters on which a particular emphasis must be paid. The Sobol's method is a global and model independent sensitivity analysis method that quantifies the amount of variance that each parameter contributes to the unconditional variance of the model output. The parameters' values, the distribution, and the experimental design were the same as for the uncertainty analysis. We then calculated the first order ( $S i$; variance contribution of one parameter to the total model variance) and total order $(S T i$; result of the main effect of one parameter and 
Table 1: C. elegans DEBtox equations

Assimilation model:

$$
\begin{aligned}
& \frac{d l}{d t}=r_{B} \frac{\left(1-s_{f}\right) f+g}{g+\left[\left(1-s_{f}\right) f\left(1-s\left(c_{q}\right)\right)\right]}\left[\left(1-s_{f}\right) f\left(1-s\left(s_{q}\right)\right)-l\right] \\
& \frac{d R}{d t}=\frac{R_{M}}{1-l_{p}^{3}}\left[\frac{g+l}{g+\left(1-s_{f}\right) f\left(1-s\left(c_{q}\right)\right)}\left(1-s_{f}\right) f\left(1-s\left(c_{q}\right)\right) l^{2}-l_{p}^{3}\right] \frac{R_{M a x}-R}{R_{M a x}}
\end{aligned}
$$

Maintenance model:

$$
\begin{aligned}
& \frac{d l}{d t}=r_{B}\left[\left(1-s_{f}\right) f-\left(1+s\left(c_{q}\right)\right) l\right] \\
& \frac{d R}{d t}=\frac{R_{M}}{1-l_{p}^{3}}\left(1+s\left(c_{q}\right)\right)\left[\left(1-s_{f}\right) f l^{2} \frac{g\left(1+s\left(c_{q}\right)\right)^{-1}+l}{g+\left(1-s_{f}\right) f}-l_{p}^{3}\right] \frac{R_{\text {Max }}-R}{R_{\text {Max }}}
\end{aligned}
$$

Growth model:

$$
\begin{aligned}
& \frac{d l}{d t}=r_{B} \frac{\left(1-s_{f}\right) f+g}{\left(1-s_{f}\right) f+g\left(1+s\left(c_{q}\right)\right)}\left[\left(1-s_{f}\right) f-l\right] \\
& \frac{d R}{d t}=\frac{R_{M}}{1-l_{p}^{3}}\left[\left(1-s_{f}\right) f l^{2} \frac{g\left(1+s\left(c_{q}\right)\right)+l}{g\left(1+s\left(c_{q}\right)\right)+\left(1-s_{f}\right) f}-l_{p}^{3}\right] \frac{R_{M a x}-R}{R_{M a x}}
\end{aligned}
$$

Hazard model:

$$
\begin{aligned}
& \frac{d l}{d t}=r_{B}\left[\left(1-s_{f}\right) f-l\right] \\
& \frac{d R}{d t}=\frac{R_{M}}{1-l_{p}^{3}}\left[\left(1-s_{f}\right) f l^{2} \frac{g+l}{g+\left(1-s_{f}\right) f}-l_{p}^{3}\right] \exp ^{-s\left(c_{q}\right)} \frac{R_{M a x}-R}{R_{M a x}}
\end{aligned}
$$

Costs model:

$$
\begin{aligned}
& \frac{d l}{d t}=r_{B}\left[\left(1-s_{f}\right) f-l\right] \\
& \frac{d R}{d t}=\frac{R_{M}}{1-l_{p}^{3}}\left[\left(1-s_{f}\right) f l^{2} \frac{g+l}{g+\left(1-s_{f}\right) f}-l_{p}^{3}\right]\left(1+s\left(c_{q}\right)\right)^{-1} \frac{R_{M a x}-R}{R_{M a x}}
\end{aligned}
$$


of all its interactions with the other parameters) Sobol index. Calculations were performed thanks to the function "sobol2002" from the sensitivity R-package (Pujol et al., 2012) with the statistical computing software R 2.15 (R Core Team, 2012).

\section{Results}

\subsection{Control data fit accuracy}

Our model (Eq. 1) provided a relevant fit of both the growth and the reproduction data for the control conditions (Fig 1A and B). The parameters we obtained by fitting the control data set are presented in Table 2 . Both our model and the model proposed by Jager et al. $(2005)$ present a similar fit accuracy $(\Delta \mathrm{DIC}<5$, see Table S2).

Uncertainty analysis performed on the model proposed by Jager et al. (2005) showed that this model does not allow growth of hatchlings at suboptimal food availabilities. Indeed, more than $50 \%$ of the simulated cases gave a non growing and therefore a non reproductive nematode (Fig. S1A and S2A). In contrast, our model allows the hatchlings nematodes to grow at much lower food levels (Eq. 1) (Fig. S1B and S2B). Model exploration also showed that the model we used is robust for the parameters estimations. Indeed, as shown by the Figures S1C and D, our model allows to test a larger range of values leading to a significant growth, while performing the parameters estimations, compared to the initial model proposed by Jager et al. (2005).
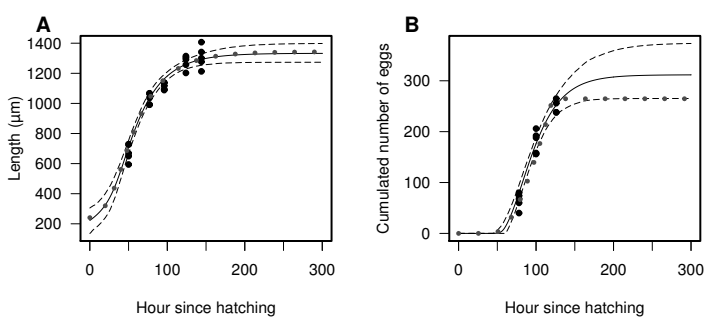

Figure 1: C. elegans length (A) and cumulated reproduction $(\mathbf{B})$ in relation to age for the control conditions. Age is indicated as hour since hatching. Observed data are represented by points, the model fits (Eq. 1) are represented by the regression line. Dashed lines represent 95 th percentiles of the posterior distribution. Dotted lines represent the model fitted with the equations of Jager et al. (2005).

\subsection{Mode of action and sensitivity anal- ysis}

Table S2 presents the DIC comparison between the model by Jager et al. (2005) and our model for all the modes of action. The best mode of action is the assimilation model. Indeed, the DIC of the assimilation model is lower by over 32 points than all other modes of action DIC. In the same way as for the control model, the Jager et al. (2005) model and our model have a non distinguishable quality of fit $(\Delta \mathrm{DIC}<5)$ for the assimilation model.

Sensitivity analysis (Fig. 2 and S3) performed on our assimilation model showed that the main impact contributors to the growth model (Eq. 3a) output variations are parameters $\alpha(-)$ and the exposure concentration, followed by parameters $b\left(\mathrm{mM}^{-1}\right), f(-)$, $L_{f}(\mu \mathrm{m})$, and NEC (mM). Although $L_{f}(\mu \mathrm{m})$ has a non negligible $S T i$, its $S i$ remains negligible. Parameters $R_{M a x}(\#), L_{p}(\mu \mathrm{m}), R_{M}\left(\# \mathrm{~h}^{-1}\right)$, and $g(-)$ did not influence the growth model output. Regarding the reproduction model (Eq. 3b), parameters $f(-)$ and the exposure concentration are the main contributors. These parameters are followed by parameters $b\left(\mathrm{mM}^{-1}\right), \alpha(-), L_{i n f}(\mu \mathrm{m}), L_{p}(\mu \mathrm{m})$, and $N E C(\mathrm{mM})$. Parameters $L_{0}(\mu \mathrm{m}), R_{M}\left(\# \mathrm{~h}^{-1}\right), R_{M a x}(\#)$, and $g(-$ ) did not influence the reproduction model output.
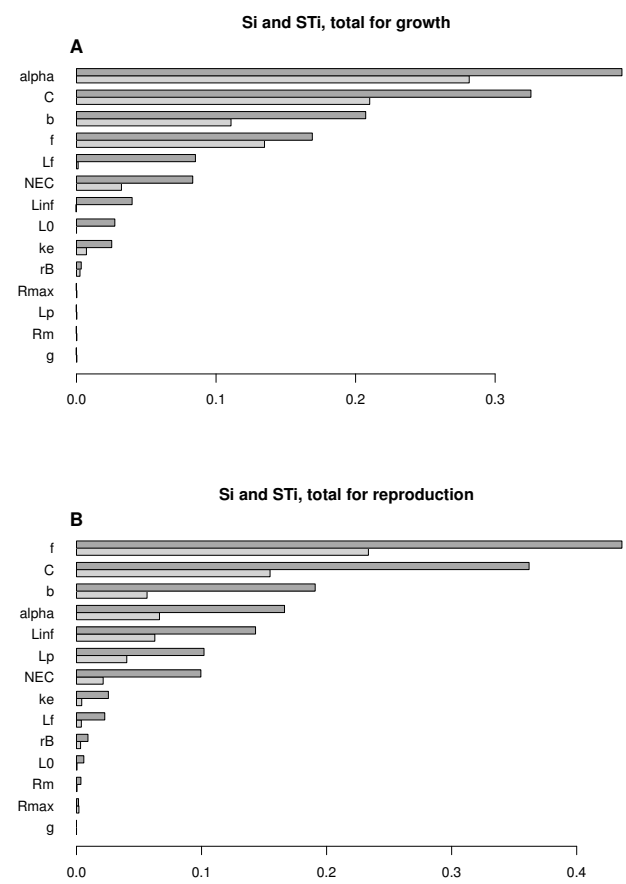

Figure 2: Sensitivity analysis for the assimilation model (Eq. 3). Mean of the sensitivity indices at the different times for the growth equation (A) and reproduction equation (B). Total order indices $(S T i)$ are presented in dark grey and first order indices $(S i)$ in light grey. Parameters were ordered according to the total order Sobol sensitivity indices.

\subsection{Parameter estimations}

Parameter estimations for the assimilation mode of action (Eq. 3) are presented in Table 2 and Figure S4. The distributions of the parameters estimated with the control data only were close to the distributions of the parameters estimated with all the data. Indeed, 
Table 2: Prior and posterior (mean $\pm \mathrm{SD}$ ) distributions of the model parameters using the assimilation model (Eq. 3)

\begin{tabular}{llrr} 
Parameter & Prior & $\begin{array}{r}\text { Control data set } \\
\text { (mean } \pm \text { SD) }\end{array}$ & $\begin{array}{r}\text { Full data set } \\
\text { (mean } \pm \text { SD) }\end{array}$ \\
\hline$\alpha(-)$ & $U[0,1]$ & $0.88 \pm 0.07$ & $0.86 \pm 0.06$ \\
$f(-)$ & $U[0,1]$ & $0.97 \pm 0.02$ & $0.97 \pm 0.03$ \\
$L_{0}(\mu \mathrm{m})$ & $\mathcal{N}(282,56) \mathrm{I}] 0,+\infty]$ & $219 \pm 43.53$ & $165 \pm 37.37$ \\
$L_{f}(\mu \mathrm{m})$ & $\mathcal{N}(444,89) \mathrm{I}] 0,+\infty]$ & $418 \pm 50.96$ & $364 \pm 47.35$ \\
$L_{p}(\mu \mathrm{m})$ & $\mathcal{N}(1020,204) \mathrm{I}] 0,+\infty]$ & $764 \pm 87.18$ & $818 \pm 57.64$ \\
$L_{\text {inf }}(\mu \mathrm{m})$ & $\mathcal{N}(1540,308) \mathrm{I}] 0,+\infty]$ & $1414 \pm 46.32$ & $1383 \pm 41.14$ \\
$r_{B}\left(\mathrm{~h}^{-1}\right)$ & $\left.\left.\mathcal{N}\left(0.039,7.810^{-3}\right) \mathrm{I}\right] 0,+\infty\right]$ & $0.034 \pm 0.005$ & $0.031 \pm 0.003$ \\
$g(-)$ & $U[0,20]$ & $10 \pm 5.48$ & $12 \pm 4.88$ \\
$R_{M}(\# \mathrm{~h}-1)$ & $\mathcal{N}(12.67,2.53) \mathrm{I}] 0,+\infty]$ & $15.8 \pm 2.02$ & $15.1 \pm 1.90$ \\
$R_{M a x}(\#)$ & $\mathcal{N}(265,53) \mathrm{I}] 0,+\infty]$ & $312 \pm 27.42$ & $249 \pm 22.13$ \\
$k_{e}\left(\mathrm{~h}^{-1}\right)$ & $U[0,1]$ & - & $0.16 \pm 0.11$ \\
$b\left(\mathrm{mM}^{-1}\right)$ & $U[0,5]$ & - & $0.31 \pm 0.03$ \\
$N E C(\mathrm{mM})$ & $U[0,2]$ & - & $0.42 \pm 0.06$ \\
\hline Prior & & - & - \\
\hline
\end{tabular}

Prior and posterior (mean $\pm \mathrm{SD}$ ) distributions of the model parameters using the assimilation model (Eq. 3) with the control data only or with all data (Full data set). The normal distribution of mean $\mu$ and standard deviation $\sigma$ is noted $\mathcal{N}(\mu, \sigma)$, and the uniform distribution between $a$ and $b$ is noted $U[a, b]$. I $] c, d]$ denotes an interval censoring between $c$ (excluded) and $d$

the means of the parameters estimates were within the confidence interval of each other. According to these estimations, the individuals were mostly fed ad libitum $(f=0.97)$. The estimated no-effect concentration $(N E C(\mathrm{mM}))$ was of $0.42 \pm 0.06 \mathrm{mM}$ and the elimination rate $k_{e}\left(\mathrm{~h}^{-1}\right)$ was of $0.16 \pm 0.11 \mathrm{~h}^{-1}$ indicating that under continuous exposure, internal concentration steady state should be reached within one day. The slope of the effect $\left(b\left(\mathrm{mM}^{-1}\right)\right)$ was estimated at $0.31 \pm 0.03$. The slope of the effect $\left(b\left(\mathrm{mM}^{-1}\right)\right)$ and the no-effect concentration $(N E C(\mathrm{mM}))$ were slightly correlated (correlation coefficient of 0.17 ). The newly introduced parameter $\alpha(-)$ was estimated at $0.88 \pm 0.07$ for the control data set and at $0.86 \pm 0.06$ for all the data.

As shown in Figure 3, uranium affects both growth (especially the individuals' maximum length) and reproduction (both the onset of the reproduction and the maximum cumulated reproduction).

\section{Discussion}

In this study, the effect of uranium on growth and reproduction of the nematode $C$. elegans has been assessed using a bioenergetic approach.

We have shown that our model presents a relevant fit for $C$. elegans growth and reproduction. The model we used presents a similar fit quality to the model proposed by Jager et al. $(2005)(\Delta \mathrm{DIC}<5)$. Nevertheless, our model has been shown to be more robust and to better account for the end of the reproductive period. Our model was more flexible, allowed a larger variation around the optimal values, and therefore, could handle a larger range of biological possibilities. Indeed, as shown in Figure S1C, the previous model did not allow growth for organisms slightly limited $(f \leq 0.9)$ around the $L_{f}(\mu \mathrm{m})$ optimal values presented by Jager et al. $(2005)(\approx 444 \mu \mathrm{m})$. Nevertheless, as demonstrated by Palgunow et al. (2012), C. elegans can handle a large variation of feeding conditions. These authors submitted wild-type N2 nematodes to a so-called "developmental-Dietary Restriction" (dDR) experiment (organisms fed by $250 \mu \mathrm{L}$ E. coli, $\mathrm{OD}_{600}$ ranging from 0.3 to 6 , dDR starting from egg stage) and did not observed any arrest of growth (the authors observed a reduction of $74 \%$ of body length at adult stage for the most stringent dDR condition). According to Figure S1D, the new formulation allowed organisms growth for a larger range of dietary restriction. The new formulation of the reproduction is a descriptive model that also takes into account (i) the fact that sperm cells are limited since they are produced before oocytes during the early stage of development of $C$. elegans (mainly during the beginning of stage L4) (Hubbard and Greenstein, 2005; Lints and Hall, 2009) and (ii) the slow decrease of the laying at the end of the reproductive period (Byerly et al., 1976; Muschiol et al., 2009). A mechanistic understanding of this new formulation of the reproduction may be as follows: if it is assumed that an egg-laying involves an ejaculate of several male gamete, this may lead to a decrease of the density of sperm as the male gamete reserve decreases. Further experiments would be required to confirm this hypothesis. It should be necessary to be able to measure sperm density.

Our results show that uranium affects both the reproduction and the growth of $C$. elegans. Our modelling results suggest that the mode of action of uranium is an effect on the assimilation of energy from food. Indeed, the Deviance Information Criterion we obtained for the assimilation model was much better than for all other modes of action. This result is consistent with other experimental and modelling studies 

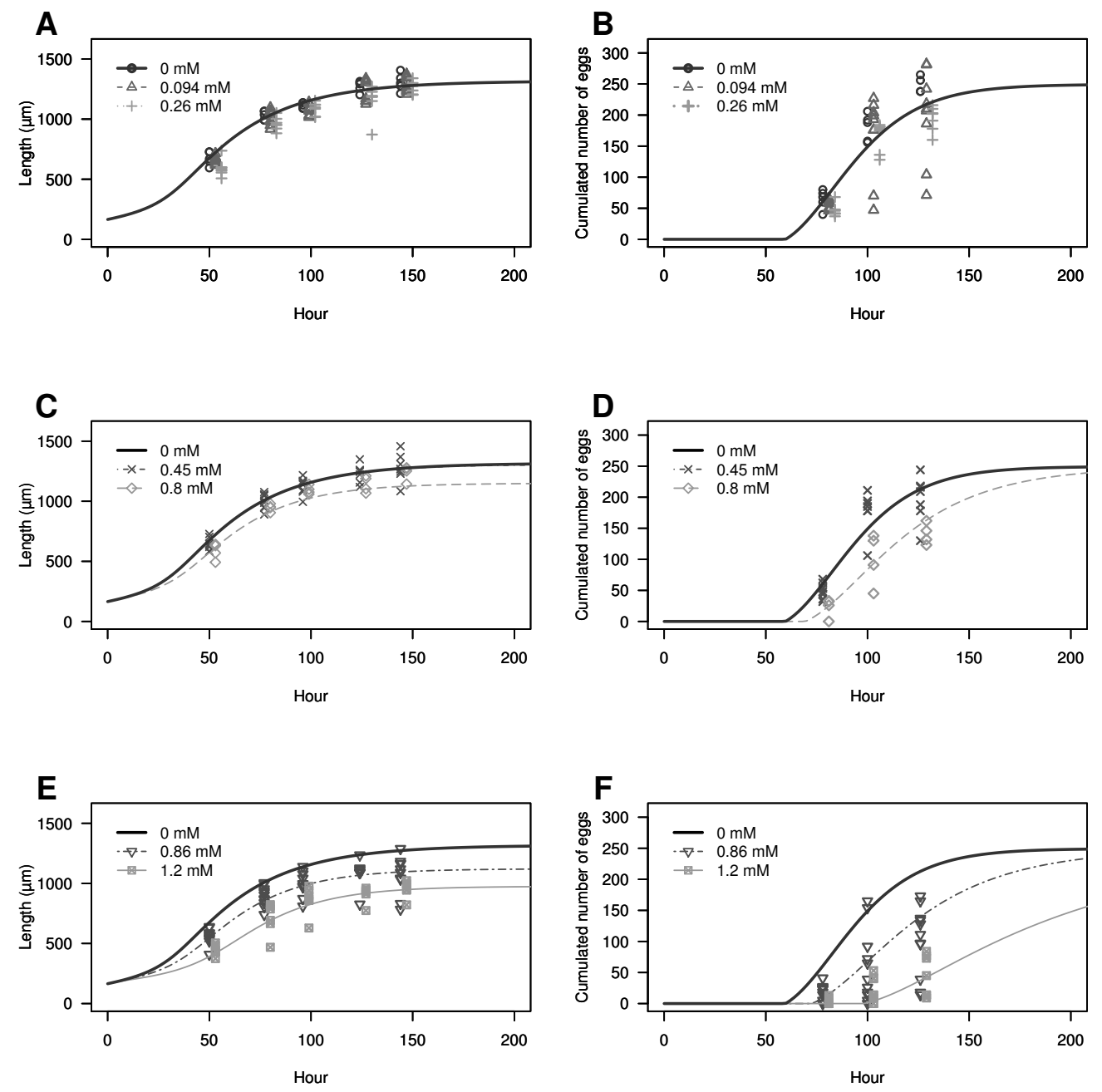

Figure 3: Growth and reproduction results for the assimilation model (Eq 3). Panels A and B represent the results for a concentration below the no-effect concentration $(N E C(\mathrm{mM}))$ for respectively the growth and the reproduction. Panels C, D (two lowest), E, and F (two highest) represent the results for the concentrations over the non effect concentration $(N E C(\mathrm{mM}))$ for the growth and the reproduction. Model fits are represented by regression lines. Data are represented by symbols. Symbols have been slightly shifted in time to facilitate graphics' reading.

which tackled the mode of action of uranium. Augustine et al. (2012a) showed that the mode of action of uranium on Danio rerio could either be assimilation or maintenance. A complementary study reveals that uranium induced an increase of damage in gut cell mitochondria, a loss of the gut wall architecture, the presence of large necrotic zones, and an overall decrease in gut bacteria (Augustine et al., 2012b). As these results reveal negative impacts on organs linked with the assimilation of food, they are in accordance with effects on the assimilation of energy from food. Similarly, DEBtox analysis of the uranium toxicity on Daphnia magna exposed during three generations showed that for the two first generations, the assimilation and the maintenance captured effects on growth and reproduction equally well, but for the last generation, the assimilation mode of action better captured the uranium effects (Massarin et al., 2011). The authors concluded in favour of the assimilation mode of action based on this last result and on histological evidences. These results were indeed supported by measurements demonstrating that uranium induced structural damages on intestinal epithelium (Massarin et al., 2011; Zeman, 2008), a significant decrease of the ingestion rate expressed per daphnid (Zeman et al., 2008), and a significant reduction in carbon ingestion and assimilation rates (Massarin et al., 2010). The same kind of histological damages to the digestive tract was also reported on the earthworm Eisenia fetida exposed to soil contaminated with uranium (Giovanetti et al., 2010).

Our conclusions relative to the mode of action are based on "goodness of fit" and on information from the literature. Using "goodness of fit" only would have required complementary experiments. Indeed, the outcome of the comparison between different modes of action may be biased by experimental variability. Another important point is that, in DEBtox modelling, 
the level of effects is assumed to be linearly dependent on the internal concentration, once the NEC is exceeded. This is a strong assumption to account for the actual shape of the dose response with a minimum set of parameters to estimate. This may bias the comparison between different modes of action, if the actual dose response is far from linear. Thereby, previous studies assessing modes of action through DEBtox models proposed complementary measures to a standard test such as food limitation studies or histological observations (Massarin et al., 2011).

Even though we obtained a biologically pertinent model, it did not fit very well the maximum egg laying under stress conditions. A better fit may be obtained using a double effect (both direct and indirect effect) on the $C$. elegans reproduction (Table S1). Thereby a hazard additional effect (Eq. S1) or a cost additional effect (Eq. S2) on the male gametes could be considered in addition with the assimilation model (Eq. 3).

Applied to our data, Eq. S1 gave a DIC of 4,398 and Eq. S2 a DIC of 4,399. Although these DIC are lower than the DIC we obtained in Table S2, to conclude with certainty, and retain this model, further experimental analysis are required to assess and validate this double effect. It should be interesting to assess the evolution of the number of male gamete produced under uranium exposure through, for example, the use of DAPI staining and counting spermatid nuclei located within the gonad as described by Cutter (2004).

The sensitivity analysis we performed showed that the parameters related to food assimilation such as $f$ () and $\alpha(-)$ greatly influence the model output. Indeed, according to the DEB framework, food assimilation is the main organism function for the acquisition of energy, and therefore, this function drives all other organism functions. Thereby we believe that the food distribution must be constant throughout the replicates and conditions in toxicity test experiments. Moreover, the food linked parameters should be re-estimated during the data analysis. The impacts of the variations of exposure concentration on the model output were also assessed thanks to the sensitivity analysis. As this parameter is one of the most influential parameters on the output variability of the model, we recommend the careful analysis of the actual concentration present in the medium.

\section{Conclusion}

Our study proposed a robust and consistent DEB model for the nematode. Our results supported the hypothesis that uranium affects the assimilation of energy from food in many species. We also confirmed the importance of accurately assessing the actual exposure concentration of contaminant and of food while analysing (toxicity) data through modelling. We highlight some points of attention when using modelling for assessing (eco)toxicological data such as the importance of supporting the modelling results by comple- mentary studies. The model developed and evaluated in the present study appears suitable to be used in the analysis of multi-generational datasets such as the one we recently produced (Goussen et al., 2013) in order to assess the evolution of individuals exposed to long term stress.

\section{Acknowledgement}

We are especially grateful to Florian Parisot for experimental help, Catherine Lecomte for discussions and suggestion on this project, Audrey Sternalski for discussion and punctual help, Virginie Camilleri for technical assistance with the ICP-AES measurements, and Cleo Tebby for linguistic corrections and discussion. We also thank Henrique Teotónio for providing us with his base population and for comments. We also thanks two anonymous reviewers who helped us to greatly improve the manuscript. This work was part of the Envirhom-Eco research program supported by the French Institute for Radioprotection and Nuclear Safety (IRSN) and the 190 program supported by the French Ministry of Ecology. 


\section{References}

Abada, E., Sung, H., Dwivedi, M., Park, B.J., Lee, S.K., Ahnn, J., 2009. C. elegans behavior of preference choice on bacterial food. Molecules and Cells 28, 209-213. doi:10.1007/s10059-009-0124-x.

Alda Álvarez, O., Jager, T., Colao, B.N., Kammenga, J.E., 2006. Temporal Dynamics of Effect Concentrations. Environ Sci Technol 40, 2478-2484. doi:10.1021/es052260s. pMID: 16646492.

Alda Álvarez, O., Jager, T., Kooijman, S.A.L.M., Kammenga, J.E., 2005. Responses to stress of Caenorhabditis elegans populations with different reproductive strategies. Funct Ecol 19, 656-664. doi:10.1111/j.1365-2435.2005.01012.x.

Augustine, S., Gagnaire, B., Adam-Guillermin, C., Kooijman, S.A.L.M., 2012a. Effects of uranium on the metabolism of zebrafish, Danio rerio. Aquat Toxicol 118-119, 9-26. doi:10.1016/j . aquatox.2012.02.029.

Augustine, S., Pereira, S., Floriani, M., Camilleri, V., Gagnaire, B., Kooijman, S.A.L.M., Adam-Guillermin, C., 2012b. Uranium induces ultra structural damage to gut wall of zebrafish, Danio rerio, in: Augustine, S. (Ed.), Metabolic programming of zebrafish, Danio rerio, uncovered; physiological performance as explained by Dynamic Energy Budget theory and life cycle consequences of uranium induced perturbations.. Ph.D. Thesis 6, pp. 107-119. URL: http://tel.archives-ouvertes.fr/tel-00761088.

Beaudouin, R., Dias, V., Bonzom, J.M., Péry, A.R.R., 2012. Individual-based model of Chironomus riparius population dynamics over several generations to explore adaptation following exposure to uraniumspiked sediments. Ecotoxicology 21, 1225-1239. doi:10.1007/s10646-012-0877-4. 10.1007/s10646012-0877-4.

Billoir, E., Delignette-Muller, M.L., Péry, A.R.R., Charles, S., 2008a. A Bayesian Approach to Analyzing Ecotoxicological Data. Environ Sci Technol 42, 8978-8984. doi:10.1021/es801418x.

Billoir, E., Delignette-Muller, M.L., Péry, A.R.R., Geffard, O., Charles, S., 2008b. Statistical cautions when estimating DEBtox parameters. J Theor Biol 254, 55-64. doi:10.1016/j.jtbi.2008.05.006.

Boyd, W.A., McBride, S.J., Rice, J.R., Snyder, D.W., Freedman, J.H., 2010. A high-throughput method for assessing chemical toxicity using a Caenorhabditis elegans reproduction assay. Toxicology and Applied Pharmacology 245, 153-159. doi:10.1016/j.taap.2010.02.014.

Byerly, L., Cassada, R.C., Russell, R.L., 1976. The life cycle of the nematode Caenorhabditis elegans : I. Wild-type growth and reproduction. Dev Biol 51, 23-33. doi:10.1016/0012-1606 (76) 90119-6.
Cutter, A.D., 2004. Sperm-limited fecundity in nematodes: How many sperm are enough? Evolution 58, 651-655. doi:10.1554/03-421.

Dutilleul, M., Lemaire, L., Réale, D., Lecomte, C., Galas, S., Bonzom, J.M., 2013. Rapid phenotypic changes in Caenorhabditis elegans under uranium exposure. Ecotoxicology 22, 862-868. doi:10.1007/s10646-013-1090-9.

Giovanetti, A., Fesenko, S., Cozzella, M.L., Asencio, L.D., Sansone, U., 2010. Bioaccumulation and biological effects in the earthworm Eisenia fetida exposed to natural and depleted uranium. J Environ Radioact 101, 509-516. doi:10.1016/j.jenvrad.2010.03.003.

Goussen, B., Parisot, F., Beaudouin, R., Dutilleul, M., Buisset-Goussen, A., Péry, A.R.R., Bonzom, J.M., 2013. Consequences of a multi-generation exposure to uranium on Caenorhabditis elegans life parameters and sensitivity. Ecotoxicology 22, 869-878. doi:10.1007/s10646-013-1078-5.

Hubbard, E.J.A., Greenstein, D., 2005. Introduction to the germ line (september 1, 2005), in: WormBook (Ed.), WormBook. The C. elegans Research Community, WormBook. doi:10.1895/wormbook.1.18.1.

Jager, T., Alda Álvarez, O., Kammenga, J.E., Kooijman, S.A.L.M., 2005. Modelling nematode life cycles using dynamic energy budgets. Funct Ecol 19, 136144. doi:10.1111/j.0269-8463.2005.00941.x.

Jager, T., Crommentuijn, T., van Gestel, C.A.M., Kooijman, S.A.L.M., 2004. Simultaneous Modeling of Multiple End Points in Life-Cycle Toxicity Tests. Environ Sci Technol 38, 2894-2900. doi:10.1021/es0352348. pMID: 15212265.

Knight, C.G., Patel, M.N., Azevedo, R.B.R., Leroi, A.M., 2002. A novel mode of ecdysozoan growth in Caenorhabditis elegans. Evol Dev 4, 16-27. doi:10.1046/j.1525-142x.2002.01058.x.

Kooijman, S.A.L.M., 2010. Dynamic Energy Budget Theory for Metabolic Organisation. Third ed., Cambridge University Press, Cambridge. ISBN 9780521131919.

Kooijman, S.A.L.M., Bedaux, J.J.M., 1996. Analysis of toxicity tests on Daphnia survival and reproduction. Water Res 30, 1711-1723. doi:10.1016/0043-1354(96)00054-1.

Lints, R., Hall, D., $2009 . \quad$ Reproductive system, germ line, in: WormAtlas. WormAtlas, http://www.wormatlas.org. doi:10.3908/wormatlas.1.23.

Martin, B.T., Jager, T., Nisbet, R.M., Preuss, T.G., Hammers-Wirtz, M., Grimm, V., 2013. Extrapolating ecotoxicological effects from individuals to populations: a generic approach based on 
Dynamic Energy Budget theory and individualbased modeling. Ecotoxicology 22, 574-583. doi:10.1007/s10646-013-1049-x.

Massarin, S., Alonzo, F., Garcia-Sanchez, L., Gilbin, R., Garnier-Laplace, J., Poggiale, J.C., 2010. Effects of chronic uranium exposure on life history and physiology of Daphnia magna over three successive generations. Aquat Toxicol 99, 309-319. doi:10.1016/j.aquatox.2010.05.006.

Massarin, S., Beaudouin, R., Zeman, F., Floriani, M., Gilbin, R., Alonzo, F., Pery, A.R.R., 2011. Biology-Based Modeling To Analyze Uranium Toxicity Data on Daphnia magna in a Multigeneration Study. Environ Sci Technol 45, 4151-4158. doi:10.1021/es104082e.

Maupas, E., 1900. Modes et formes de reproduction des nématodes. Archives de Zoologie Expérimentale et Générale 8, 463-624.

Muschiol, D., Schroeder, F., Traunspurger, W., 2009. Life cycle and population growth rate of Caenorhabditis elegans studied by a new method. BMC Ecology 9, 14. doi:10.1186/1472-6785-9-14.

OECD, International Atomic Energy Agency (IAEA), 2012. Uranium 2011 Resources, Production and Demand. OECD Publishing. ISBN 9789264178038.

Palgunow, D., Klapper, M., Döring, F., 2012. Dietary restriction during development enlarges intestinal and hypodermal lipid droplets in Caenorhabditis elegans. PLoS ONE 7, e46198. doi:10.1371/journal pone.0046198.

Péry, A.R.R., Bedaux, J.J.M., Zonneveld, C., Kooijman, S.A.L.M., 2001. Analysis of bioassays with time-varying concentrations. Water Research 35, 3825-3832. doi:10.1016/S0043-1354(01)00106-3.

Plummer, M., 2003. JAGS: A program for analysis of Bayesian graphical models using Gibbs sampling, in: Proceedings of the 3rd International Workshop on Distributed Statistical Computing (DSC 2003). March, pp. 20-22.

Pujol, G., Iooss, B., Janon, A., 2012. sensitivity: Sensitivity Analysis. URL: http: //CRAN.R-project. org/package=sensitivity. r package version 1.6-1.

R Core Team, 2012. R: A Language and Environment for Statistical Computing. R Foundation for Statistical Computing. Vienna, Austria. URL: http: //www.R-project.org/. ISBN 3-900051-07-0.

Saltelli, A., 2002. Making best use of model evaluations to compute sensitivity indices. Comput Phys Commun 145, 280-297. doi:10.1016/S0010-4655(02)00280-1.
Sheppard, S.C., Sheppard, M.I., Gallerand, M.O., Sanipelli, B., 2005. Derivation of ecotoxicity thresholds for uranium. J Environ Radioact 79, 55-83. doi:10.1016/j.jenvrad.2004.05.015.

Smith, M.V., Boyd, W.A., Kissling, G.E., Rice, J.R., Snyder, D.W., Portier, C.J., Freedman, J.H., 2009. A Discrete Time Model for the Analysis of MediumThroughput C. elegans Growth Data. PLoS ONE 4, e7018. doi:10.1371/journal.pone.0007018.

Spiegelhalter, D.J., Best, N., Carlin, B., van der Linde, A., 2002. Bayesian measures of model complexity and fit. J R Stat Soc Series B Stat Methodol 64, 583-616. doi:10.1111/1467-9868.00353. annual Meeting of the Royal-Statistical-Society, LONDON, ENGLAND, MAY 13-22, 2002.

Spiegelhalter, D.J., Thomas, A., Best, N., Lunn, D., 2003. WinBUGS User Manual - Version 1.4, January 2003. Technical Report. MRC Biostatistics Unit. Cambridge, UK.

Swain, S., Wren, J.F., Stürzenbaum, S.R., Kille, P., Morgan, A.J., Jager, T., Jonker, M.J., Hankard, P.K., Svendsen, C., Owen, J., Hedley, B.A., Blaxter, M., Spurgeon, D.J., 2010. Linking toxicant physiological mode of action with induced gene expression changes in Caenorhabditis elegans. BMC Syst Biol 4. doi:10.1186/1752-0509-4-32.

Ward, S., Carrel, J.S., $1979 . \quad$ Fertilization and sperm competition in the nematode Caenorhabditis elegans. Dev Biol 73, 304-321. doi:10.1016/0012-1606(79)90069-1.

Yeates, G.W., Bongers, T., 1999. Nematode diversity in agroecosystems. Agric Ecosyst Environ 74, 113135. doi:10.1016/S0167-8809(99)00033-X.

Zeman, F.A., 2008. Toxicité d'un mélange binaire sur la daphnie Daphnia magna: Etude des effets biologiques de l'uranium et du sélénium seuls et en mélange. Ph.D. Thesis. Université Montpellier II.

Zeman, F.A., Gilbin, R., Alonzo, F., LecomtePradines, C., Garnier-Laplace, J., Aliaume, C., 2008. Effects of waterborne uranium on survival, growth, reproduction and physiological processes of the freshwater cladoceran Daphnia magna. Aquat Toxicol 86, $370-378$. doi:10.1016/j.aquatox .2007.11.018. 


\section{A Supplementary material}

\section{A.1 Test organism}

The $C$. elegans population used in this study is the EEV-A $\mathrm{A}_{0}$ population created by Teotónio et al. (2012) from a mixture of 16 wild isolates. This androdioecious population was derived through a funnel cross strategy. Briefly, two-isolate hybrids were obtained by crossing, in a pair-wise fashion, each of the wild isolates. Then, four-isolate hybrids were obtained by inter crossing in a pair-wise fashion the two-isolate hybrids. Hybridizations continued until the 16 -isolates hybrids were created. The population was then maintained over 140 generations and no significant loss of genetic diversity was observed by the authors after the recombinationselection equilibrium was mostly reached.

Prior to exposure, nematode populations were maintained at $20{ }^{\circ} \mathrm{C}, 80 \% \mathrm{RH}$ in $9 \mathrm{~cm}$ Petri dishes filled with modified nematode growth medium (NGM; use of HEPES buffer instead of potassium phosphate buffer (Dutilleul et al., 2013; Goussen et al., 2013)) seeded with Escherichia coli strain OP50 (Brenner, 1974; Stiernagle, 2006). E. coli OP50 cultures were grown overnight in L-Broth rich medium at $37^{\circ} \mathrm{C}$. Then cultures $\left(\mathrm{OD}_{600}=3\right)$ were washed twice with a $5 \mathrm{~g} \mathrm{~L}^{-1}$ $\mathrm{NaCl}$ solution in order to remove LB medium since it contains phosphate. Petri dishes were seeded with $1 \mathrm{~mL}$ of a 20:1 mixture and left overnight to allow the bacterial culture to dry. Petri dishes were then exposed to UV doses (Bio-Link Crosslinker, $\lambda=254 \mathrm{~nm}$; intensity $=200 \mu$ watt $\mathrm{m}^{-2}$ ) for 15 minutes to stop bacterial growth and to avoid uncontrolled heterogeneity in food availability between Petri dishes. To ensure nematodes were fed ad libitum they were transferred into new dishes every three days. To do so, nematodes were washed off the Petri dishes with a M9-modified solution (use of HEPES buffer instead of potassium phosphate buffer). Nematodes picked up were pooled in a $15 \mathrm{~mL}$ falcon tube and the number of individuals in a tube was estimated based on three sample drops of $5 \mu \mathrm{L}$ (Teotónio et al., 2012). The volume corresponding to 500 individuals was then transferred into new Petri dishes.

\section{A.2 Experimental conditions}

Experimental data were extracted from a previous study (Goussen et al., 2013). Briefly, individuals from the maintained population were exposed to a range of seven nominal concentrations of uranium: 0 (control), $0.1,0.3,0.5,0.9,1.1$, and $1.2 \mathrm{mM}$ U. For this purpose, 12-well tissue-plates were used. Plates were filled with modified NGM. The uranium stock solution was obtained by dilution of uranyl nitrate $\left(\mathrm{UO}_{2}\left(\mathrm{NO}_{3}\right)_{2}, 6 \mathrm{H}_{2} \mathrm{O}\right.$, Sigma-Aldrich, France). Uranium solution was added to the modified NGM just before flowing the plates. To measure real exposure concentration, $100 \mu \mathrm{L}$ of NGM samples were collected for each treatment and stored at $4{ }^{\circ} \mathrm{C}$. The samples were digested with a combina- tion of $1 \mathrm{~mL} \mathrm{HNO}_{3}$ and $1 \mathrm{~mL} \mathrm{H}_{2} \mathrm{O}_{2}$ at $90{ }^{\circ} \mathrm{C}$ prior to measurement with ICP-AES (Optima 4300 DV, Perkin-Elmer, USA; detection limit $0.04 \mu \mathrm{M})$. Around 60 gravid hermaphrodites were randomly picked up from the maintained population dishes, placed on new plates, and allowed to lay for 90 minutes. Eggs were then pooled and randomly deposited in the 12-well tissue-plates. At least 12 wells were used for each treatment (one egg per well). Survival, growth, and egg laying were monitored individually for six days. Survival was measured by stimulating each worm with a platinum transfer pick. A nematode was scored as dead if no head or body movement was triggered by three repeated stimulations (Sutphin and Kaeberlein, 2009; Swain et al., 2004). Nematodes were photographed daily using a stereomicroscope (ZEISS SteREO Discovery V20, $\times 240$ and $\times 160$ magnification respectively for juveniles and adults) coupled with a computerconnected camera (Nikon D5000). Body length was measured using the ImageJ software (Rasband, 2012) and a micrometer scale measure. Egg laying was recorded by visual scoring. The few worms that were lost by crawling off the plates or desiccating on the sides of the plates were removed from the data.

\section{A.3 Model description}

According to the DEB theory, energy is taken up from food, assimilated, and stored into reserves. This energy is then dispatched between three main processes: (i) maintenance, (ii) growth, and (iii) reproduction. Models based on the DEB theory allowing the analyse of ecotoxicological data (i.e. DEBtox models) have been built by Kooijman and Bedaux (Kooijman and Bedaux, 1996a,b,c) and corrected by Billoir et al. (2008). DEBtox models describe the perturbation of energy management when an organism is exposed to a pollutant. This kind of model assumes that the effects appear when the internal concentration exceeds a threshold called the no-effect concentration (NEC). The DEBtox models describe five modes of action of chemicals on physiological processes. Two of these have a direct effect on the reproduction and the three others have indirect effects on the reproduction in conjunction with effects on growth. The two first are the cost model (overhead costs for the creation of eggs) and the hazard model (mortality during oogenesis), and the three others are the assimilation model (decrease of the assimilation of energy from food), the maintenance model (increase of maintenance costs), and the growth model (overhead costs for the creation of growth units).

\section{A.4 Estimation of the parameters}

For each effect model, we performed an adaptive phase of 10,000 iterations. We then performed another 90,000 iterations. These iterations were performed on three independent MCMC chains. Chains' convergences were assessed using the Gelman and Rubin (1992) convergence statistic modified by Brooks and Gelman (1998). For the few estimations for which 
the convergence was not fully reached during this first run, we performed an adaptive phase of 15,000 iterations followed by 135,000 iterations on five independent MCMC chains. Model fit quality was checked by plotting the fits for both the growth and the reproduction data. This assessment was performed using the mean and confidence interval of the 1,000 calculations corresponding to the 1,000 last iterations of the estimation process. 


\section{A.5 Supplementary equations}


Table S1: C. elegans DEBtox reproduction equations with two effects

Hazard additional effect:

$$
\frac{d R}{d t}=\frac{R_{M}}{1-l_{p}^{3}}\left[\frac{g+l}{g+\left(1-s_{f}\right) f\left(1-s\left(c_{q}\right)\right)}\left(1-s_{f}\right) f\left(1-s\left(c_{q}\right)\right) l^{2}-l_{p}^{3}\right] \frac{R_{M a x} \exp ^{-s\left(c_{q}\right)}-R}{R_{M a x} \exp ^{-s\left(c_{q}\right)}}
$$

Cost additional effect:

$$
\frac{d R}{d t}=\frac{R_{M}}{1-l_{p}^{3}}\left[\frac{g+l}{g+\left(1-s_{f}\right) f\left(1-s\left(c_{q}\right)\right)}\left(1-s_{f}\right) f\left(1-s\left(c_{q}\right)\right) l^{2}-l_{p}^{3}\right] \frac{R_{\operatorname{Max}}\left(1+s\left(c_{q}\right)\right)^{-1}-R}{R_{M a x}\left(1+s\left(c_{q}\right)\right)^{-1}}
$$




\section{A.6 Supplementary Figures}



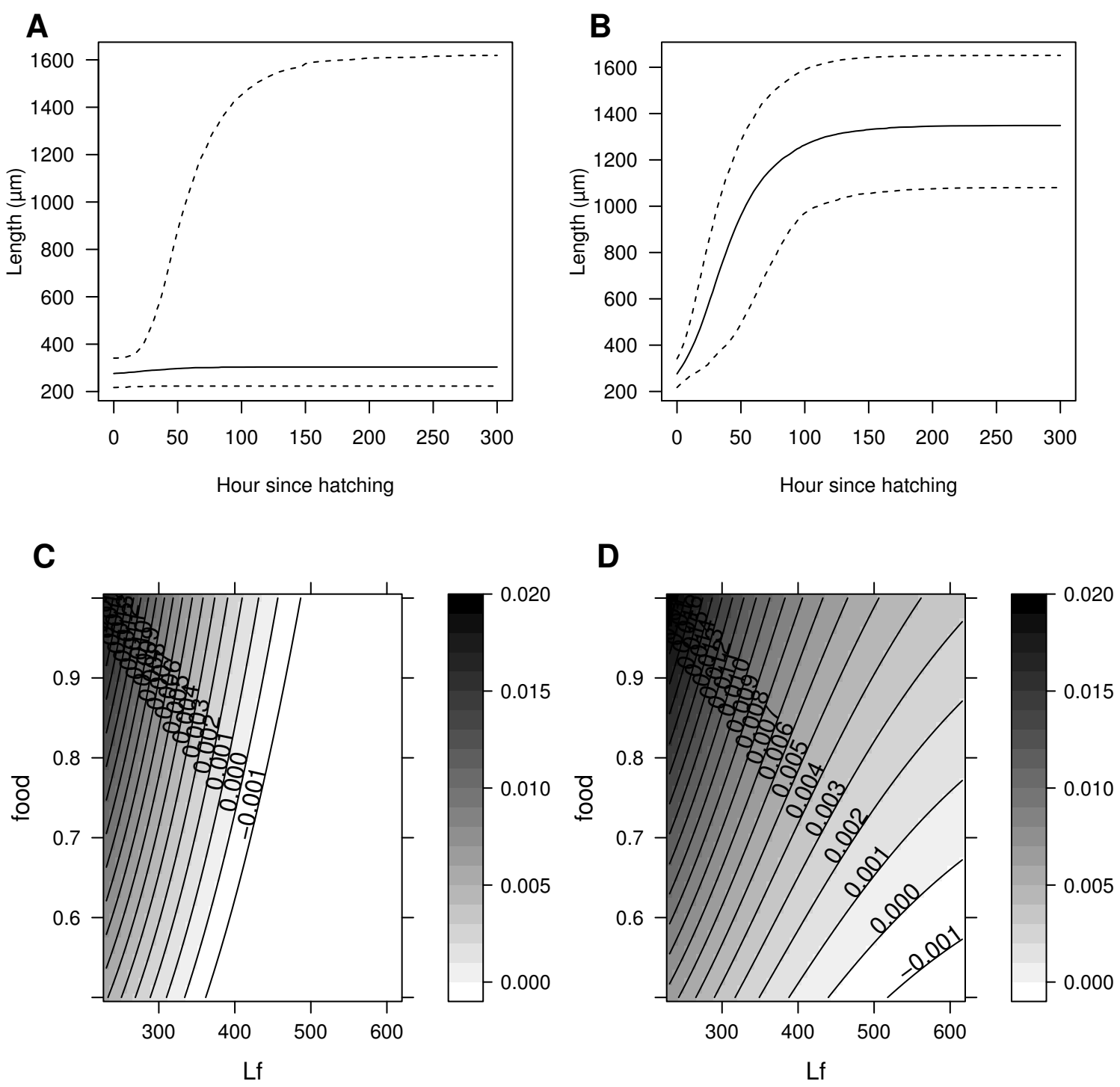

Figure S1: Uncertainty analysis and model exploration for growth. Panel A represents the uncertainty analysis of the model proposed by Jager et al. (2005) and panel B represents the uncertainty analysis of the model we used (Eq. 1). The solid line represents the median of the model output. Dashed lines represent the $95 \%$ quantiles of the model output. Panel $\mathrm{C}$ represents the scaled growth $\left(\frac{d l}{d t}\right)$ at hatching length for the model proposed by Jager et al. (2005) and panel D represents the scaled growth $\left(\frac{d l}{d t}\right)$ at hatching length for the model we used (Eq. 1). Food represents the resulting food $\left(1-s_{f}\right) f$ and Lf is the body length at which the ingestion rate is half the maximum ingestion rate. The numbers on the contours in the plot present the $\frac{d l}{d t}$ variation. $s_{f}$ includes the $\alpha(-)$ parameter in panel $\mathrm{D}$ but not in panel $\mathrm{C}$ 

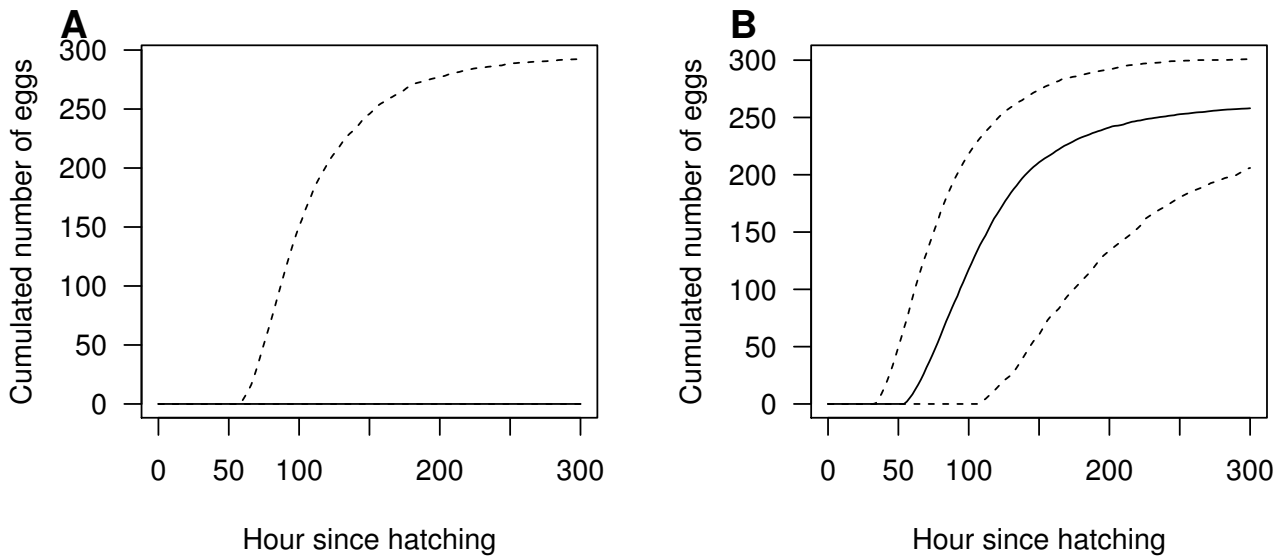

Figure S2: Uncertainty analysis for reproduction. Panel A represent the uncertainty analysis of the model proposed by Jager et al. (2005) and panel B represent the uncertainty analysis of the model we used (Eq. 1). The solid line represent the median of the model output. Dashed lines represent the $95 \%$ quantiles of the model output. 

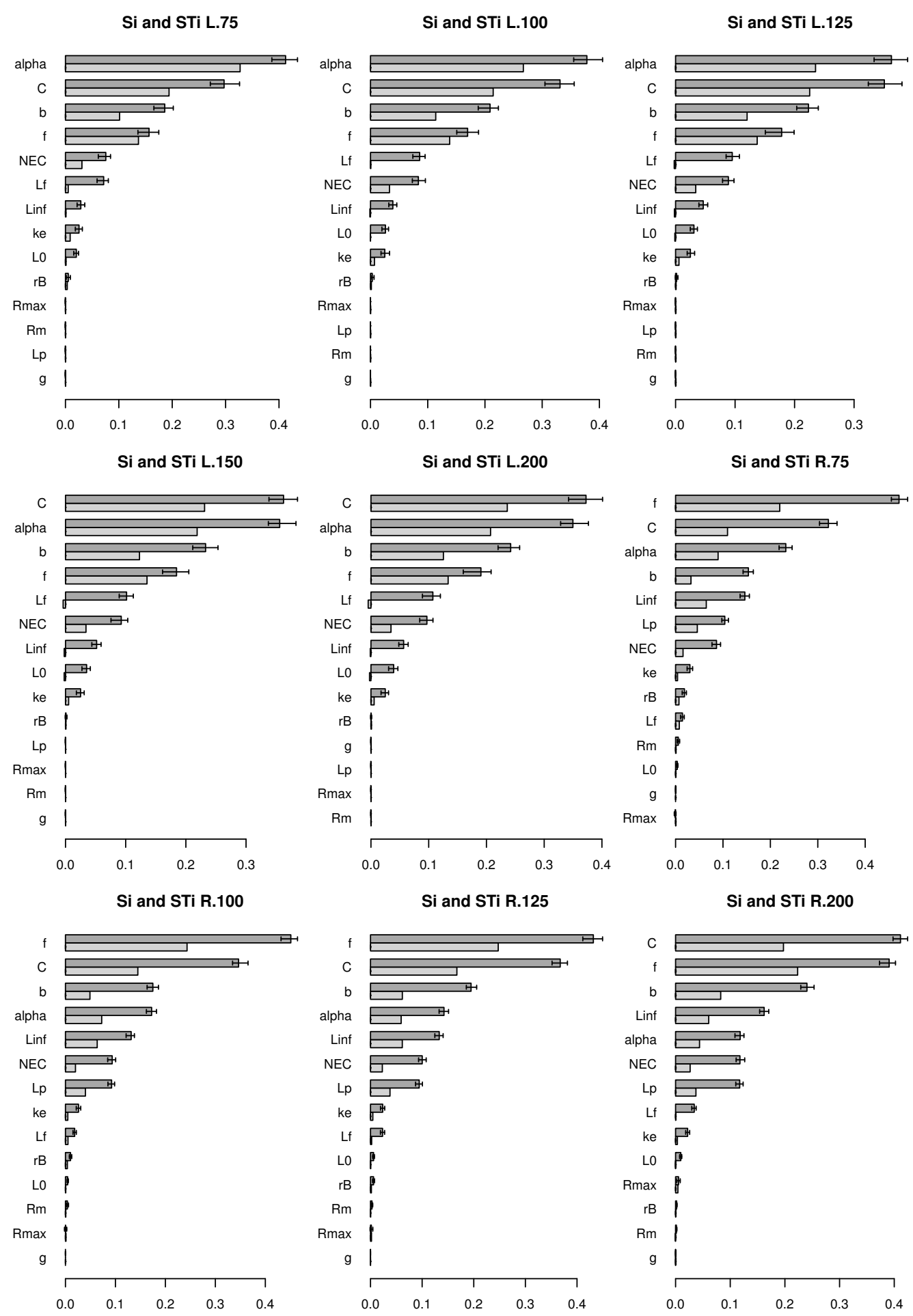

Figure S3: Sensitivity analysis for the assimilation model (Eq. 3). Sensitivity indices at the different times for the growth equation and reproduction equation (e.g. L.75 and R.75 represent respectively sensitivity indices at 75 hours for growthand reproduction equations). First order indices ( $\mathrm{Si}$ ) are presented in light grey and total order indices $(S T i)$ in dark grey. Parameters were ordered according to the total order Sobol sensitivity indices. 

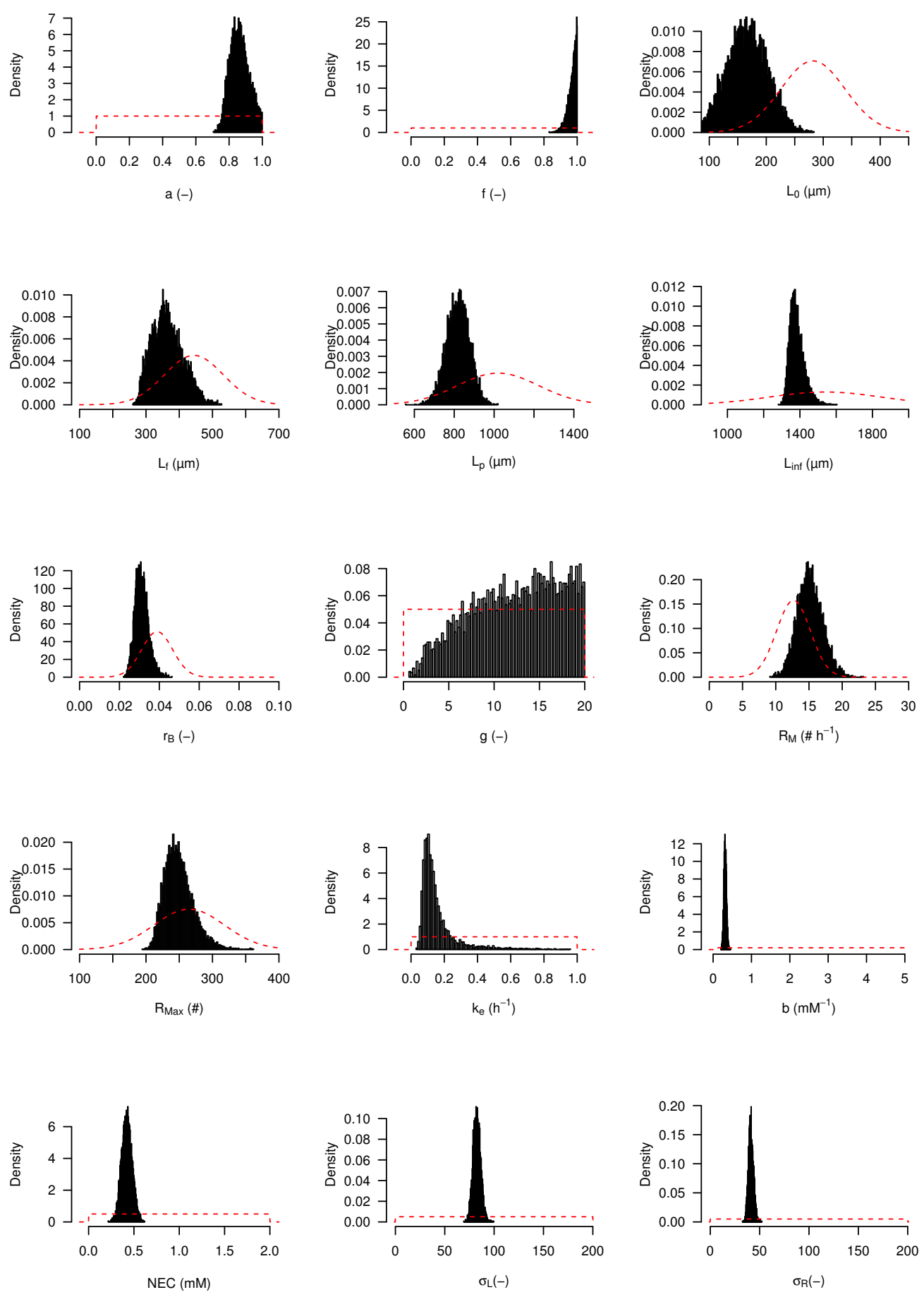

Figure S4: Prior and posterior distribution density for the assimilation model (Eq. 3). Prior distribution is presented with dashed line and posterior distribution is presented with histograms. 


\section{A.7 Supplementary Tables}


Table S2: Comparison of the fit quality between models

\begin{tabular}{llrrr} 
& Mode of action & Number of parameters & Log-likelihood & DIC \\
\hline Jager et al. (2005) & Control & 9 & -195.5 & 399 \\
& Assimilation & 12 & $-2,198.5$ & 4,408 \\
& Maintenance & 12 & $-2,227.5$ & 4,485 \\
& Growth & 12 & $-2,216.5$ & 4,451 \\
\hline Present study & Control & 10 & -196.5 & 401 \\
& Assimilation & 13 & $-2,197.0$ & 4,405 \\
& Maintenance & 13 & $-2,244.5$ & 4,687 \\
& Growth & 13 & $-2,213.0$ & 4,437 \\
\hline
\end{tabular}

Comparison between the model from Jager et al. (2005) and our model for all the modes of action. The comparison is based on the log-likelihood and the Deviance Information Criterion (DIC) 


\section{References}

Billoir, E., Delignette-Muller, M.L., Péry, A.R.R., Geffard, O., Charles, S., 2008. Statistical cautions when estimating DEBtox parameters. J Theor Biol 254, 55-64. doi:10.1016/j.jtbi.2008.05.006.

Brenner, S., 1974. Genetics of Caenorhabditis elegans. Genetics 77, 71-94.

Brooks, S.P., Gelman, A., 1998. General Methods for Monitoring Convergence of Iterative Simulations. J Comput Graph Stat 7, 434-455. doi:10.1080/10618600.1998.10474787.

Dutilleul, M., Lemaire, L., Réale, D., Lecomte, C., Galas, S., Bonzom, J.M., 2013. Rapid phenotypic changes in Caenorhabditis elegans under uranium exposure. Ecotoxicology 22, 862-868. doi:10.1007/s10646-013-1090-9.

Gelman, A., Rubin, D.B., 1992. Inference from Iterative Simulation Using Multiple Sequences. Stat Sci 7, 457-472.

Goussen, B., Parisot, F., Beaudouin, R., Dutilleul, M., Buisset-Goussen, A., Péry, A.R.R., Bonzom, J.M., 2013. Consequences of a multi-generation exposure to uranium on Caenorhabditis elegans life parameters and sensitivity. Ecotoxicology 22, 869-878. doi:10.1007/s10646-013-1078-5.

Jager, T., Alda Álvarez, O., Kammenga, J.E., Kooijman, S.A.L.M., 2005. Modelling nematode life cycles using dynamic energy budgets. Funct Ecol 19, 136144. doi:10.1111/j.0269-8463.2005.00941.x.

Kooijman, S.A.L.M., Bedaux, J.J.M., 1996a. Analysis of toxicity tests on Daphnia survival and reproduction. Water Res 30, 1711-1723. doi:10.1016/0043-1354(96) 00054-1.

Kooijman, S.A.L.M., Bedaux, J.J.M., 1996b. Analysis of toxicity tests on fish growth. Water Research 30, 1633-1644. doi:10.1016/0043-1354 (96)00057-7.

Kooijman, S.A.L.M., Bedaux, J.J.M., 1996c. The Analysis of Aquatic Toxicity Data. VU University Press. ISBN 90-5383-477-X.
Rasband, W.S., 2012. ImageJ, U. S. National Institutes of Health, Bethesda, Maryland, USA. online. URL: http://imagej.nih.gov/ij/.

Stiernagle, T., 2006. Maintenance of C. elegans, in: Wormbook. The $C$. elegans Research Community, WormBook, pp. 111. URL: http://www . wormbook.org, doi:10.1895/wormbook.1.101.1.

Sutphin, G.L., Kaeberlein, M., 2009. Measuring Caenorhabditis elegans Life Span on Solid Media. JoVE 27. doi:10.3791/1152.

Swain, S.C., Keusekotten, K., Baumeister, R., Sturzenbaum, S.R., 2004. C. elegans metallothioneins: New insights into the phenotypic effects of cadmium toxicosis. J Mol Biol 341, 951-959. doi:10.1016/j.jmb.2004.06.050.

Teotónio, H., Carvalho, S., Manoel, D., Roque, M., Chelo, I.M., 2012. Evolution of outcrossing in experimental populations of Caenorhabditis elegans. PLoS ONE 7, 1-13. doi:10.1371/journal pone.0035811. 